\title{
Fetal Echocardiography
}

\author{
Ahmet Cantug Caliskan \\ Samsun Education and Training Hospital Department of \\ Obstetrics and Gynecology Samsun \\ Turkey
}

\section{Introduction}

This is a test using sound waves to show the structure of an unborn baby's heart. An obstetrician may get a limited view of a baby's heart during a routine pregnancy ultrasound. However, a specialist in fetal echocardiography can study a baby's heart in great detail using a fetal echocardiogram.Some pregnant women are at higher risk of giving birth to a baby with a heart defect. They should be considered for referral for a specialized fetal echocardiogram. The ultrasound scanning may be done through the vagina or through the abdomen. There are no known risks to the mother or fetus.

Congenital heart disease is the most common birth defect, occurring at a rate of $8 / 1,000$ births.Because there are many different types of heart defects, ranging from minor to lifethreatening problems, examination of the fetal heart before birth has been mandated as a requirement when examining a fetus between 15 and 40 weeks of pregnancy. This has been called the Standard ultrasound evaluation of the heart and has been defined by the American College of Obstetricians and Gynecologists, the American Institute of Ultrasound in Medicine, and the American College of Radiology.In Los Angeles it has been estimated that less than $10 \%$ of serious heart defects are detected before birth when the examination is performed by an obstetrician or radiologist who does not have special training evaluating the fetal heart. Fetal Echocardiography is a more comprehensive examination of the fetal heart than the standard examination and includes identification of additional cardiac structures not defined in the standard evaluation. The physician who performs Fetal Echocardiography often uses color Doppler ultrasound and may utilize pulsed Doppler, 3D, and 4D ultrasound; depending upon the circumstances of the examination. Fetal Echocardiography is an important part of Genetic Ultrasound, a new test that identifies over $95 \%$ of fetuses with Down syndrome when performed during the second-trimester of pregnancy.

Fetal echocardiography is the primary diagnostic tool used to assess fetal cardiac structure and function.This is a specialized sonogram that is a certainly indicated when there is an increased risk of fetal cardiac abnormalites, and is usually performed at 18-22 weeks gestation.when the risk of a fetal cardiac anomaly is particularly high, an earlier evaluation, at around 13-15 weeks, by either transabdominal or vaginal sonography, may be considered, as many caardiac anomalies are already demonstrable at this stage.this early examination should, however, be corroborated by a repeat evaluation around mid-gestation. 
A complete fetal echocardiographic examination should incorporate the following Standard views:a demonstration of the visceral and cardiac situs,a four chamber view, ventriculoarterial connections, and course of the great arteries.Real-time examination of cardiac structures is enhanced by the use of color Doppler.

A baby's heart begins to develop at conception, but is completely formed by eight weeks into the pregnancy. Congenital heart defects happen during this crucial first eight weeks of the baby's development. Specific steps must take place in order for the heart to form correctly.

\section{Indications for fetal echocardiography}

\subsection{Maternal indications fetal indications}

- Family history of CHD

- Abnormal obstetrical ultrasound screen

- Metabolic disorders (eg,diabetes, PKU)

- Extracardiac abnormality

- Exposure to teratogens

- Chromosomal abnormality

- Exposure to prostaglandin synthetase inhibitors (eg,ibuprofen, salicylic acid, indomethacin)

- Arrhythmia

- Rubella infection

- Hydrops

- $\quad$ Autoimmune disease (eg,SLE, Sjogren's)

- Increased first trimester nuchal translucency

- Familial inherited disorders (Ellisvan Creveld, Marfan, Noonan's, etc)

- Multiple gestation and suspicion of twin-twin transfusion syndrome

- In vitro fertilization CHD, Congenital heart disease; PKU, phenyl ketonuria; SLE, sytemic lupus erythematosus.

While there are risk factors for congenital heart defects, over $90 \%$ of heart malformations have no known cause. For this reason researchers have classified most heart defects as multifactorial, meaning that there is no known explanation for the problem other than the possible interaction between hereditary and environmental factors. For this reason, many physicians have suggested examining all fetuses for heart defects, since most defects arise from pregnancies with no risk factors. The following lists factors associated with an increased risk for congenital heart defects. If any of these are present, the patient should be referred for Fetal Echocardiography at 18 to 24 weeks of gestation. In some cases the patient may desire first-trimester

- Fetal Echocardiography performed between 12 and 14 weeks of gestation.

- Maternal Drug Exposure and Diseases Women with seizure disorders taking anticonvulsants

- Women taking lithium for depression

- Women taking insulin for diabetes

- Women who have phenylketonuria 
- Women exposed to Rubella

- Family History of Congenital Heart Disease

- Previous child with CHD, new risk is 1 in 20 to 1 in 100

- Previous two children with CHD, new risk is 1 in 10 to 1 in 20

- $\quad$ Mother has CHD, new risk is as high as 1 in 5 to 1 in 20

- $\quad$ Father has CHD, new risk 1 in 30

- $\quad$ Increased Maternal Risk for Down Syndrome and Other Chromosomal Defects

- Advanced maternal age (>35)

- Abnormal maternal serum screening increasing risk for Downy syndrome or Trisomy 18

- Chromosome abnormalities and CHD

- Down syndrome

- $\quad$ Trisomy 18 and Trisomy 13

- Turner's syndrome

- Cri du chat syndrome

- Wolf-Hirshhorn syndrome

- $\quad$ DiGeorge syndrome (deletion 22q11)

- $\quad$ Other Rare Genetic Diseases

- Marfan syndrome

- Smith-Lemli-Opitz syndrome

- Ellis-van Creveld

- Holt-Oram syndrome

- Noonan syndrome

- Mucopolysaccharidoses

- Goldenhar syndrome (hemifacial microsomia)

- William's syndrome

- VACTERL association (tracheal and esophageal malformations associated with vertebral, anorectal,

- cardiac, renal, radial, and limb abnormalities).

- $\quad$ Ultrasound -Identified Fetal Birth Defects of the Current Pregnancy

When a birth defect is detected during an ultrasound examination, there is a higher risk for an associated defect of the fetal heart. Therefore, a fetal echocardiogram should be performed.

\subsection{Cardiovascular anatomy and fetal circulation}

After birth the circulation is divided into two separate sides that are not connected. The left side of the heart consists of the pulmonary veins, left atrium, left ventricle, and aorta. The right side of the heart consists of the superior and inferior vena cava, the right atrium, the right ventricle, and the pulmonary artery. These two circulations are independent of each other and do not connect.

However, the fetal circulation is different. The right and left sides of the heart connect at the level of the foramen ovale and the ductus arteriosus. Because of these connections fetuses can develop serious heart defects and live while in the uterus, only to be severely compromised or die because of the circulatory changes that occur following birth. To understand the effect of certain types of heart defects it is therefore important to review fetal circulation. 


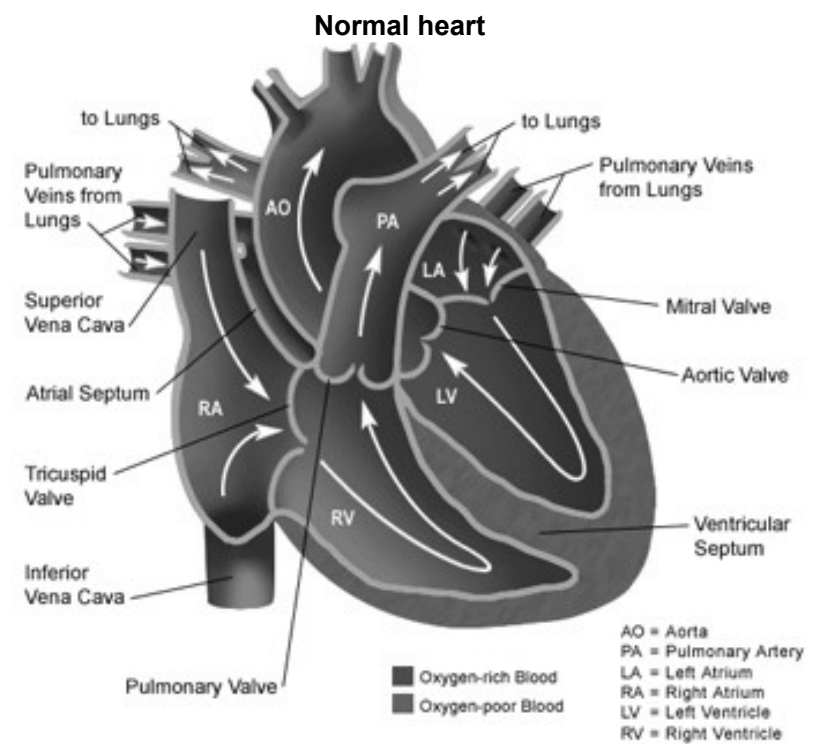

Fig. 1. Right Side of the Heart

1. Blood from the placenta returns to the fetus by the umbilical vein. The umbilical vein enters the fetal abdomen where blood continues through the intra-abdominal portion of this vessel. 2. Once inside the abdomen blood flows through the ductus venosus and is directed into the right atrial chamber. Because this blood has been enriched with oxygen and nutrients that it has picked up from the placenta, it is directed primarily through the foramen ovale into the left atrium. The foramen ovale is a small hole in the wall that separates the right and left atrial chambers. There is some mixing of blood within the right atrium.

3. The majority of blood enters the right atrium from the superior and inferior vena cava, as well as some blood from the ductus venosus (see above). The superior vena cava brings blood back from the head and upper extremities to the heart while blood from the inferior vena cava brings it back to the heart from the remainder of the body.

4. Blood is pumped from the right atrium into the right ventricle.

5. Blood from the right ventricle is pumped through the pulmonary valve into the main pulmonary artery. From here it is distributed to the lungs and to the ductus arteriosus.

6. The ductus arteriosus distributed blood to the entire body (excluding the head and upper extremities) as well as returns blood back to the placenta through the two umbilical arteries.

Left Side of the Heart

1. Blood from the placenta returns to the fetus by the umbilical vein. The umbilical vein enters the fetal abdomen where blood continues through the intra-abdominal portion of this vessel. 2. Once inside the abdomen blood flows through the ductus venosus and is directed into the right atrial chamber.Because this blood has been enriched with oxygen and nutrients that it has picked up from the placenta, it is directed through the foramen ovale into the left atrium.The foramen ovale is a small hole in the wall that separates the right and left atrial chambers

3. Once inside the left atrium the blood mixes with blood returning from the lungs and then enters the left ventricle.

4. Blood from the left ventricle is pumped into the aorta, which distributes blood to the brain and upper extremities. 
Ultrasound examination of the fetal heart was first reported in the early 1980's when 2D technology allowed the examiner to identify the four-chambers of the fetal heart.Although the value of prenatal detection of heart defects was appreciated in a theoretical sense, it has only recently been realized as a benefit. The reason for this is that the ability to detect heart defects by the physician and/or sonographer has improved as the result of training and experience COLOR DOPPLER examination of the Heart Color Doppler ultrasound is a technique that enables the physician to identify the direction and speed of blood flow within a vessel or heart chamber. Color Doppler is not part of the Standard Examination of the heart, but is used by a specialist with special training in fetal echocardiography.

The use of color Doppler ultrasound for evaluation of the fetal heart and detection of birth defects was first reported by Dr. DeVore in 1987. Since this first publication over 200 articles have been published in the medical literature describing the use of this technology for evaluating the fetal heart. Color Doppler displays the flow of blood based upon its direction of flow; red-orange towards to top of the transducer, blue away from the transducer.

The transducer is always located at the top of the image. Therefore, when blood flow is towards the transducer it is depicted in red, and away from the transducer in blue. The different hues of red-orange and blue-green indicate the different velocities or speed that blood is flowing. For example, if the color Doppler display is yellow then it is flowing towards the transducer faster than if it is deep red.

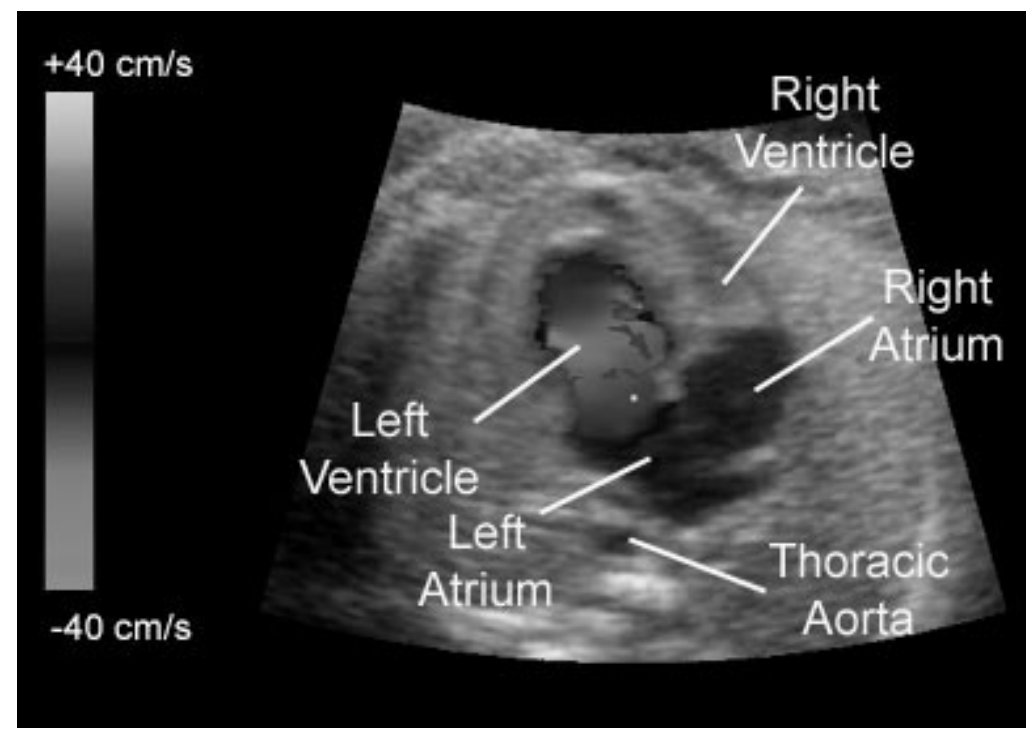

Fig. 2. This illustrates the use of color Doppler to identify the flow of blood into the ventricles.

\section{Doppler waveforms analyzed}

Measurement of the Doppler waveforms is compared to the age of the fetus. The following graphs illustrate the normal distribution of measurements for the waveforms recorded from the fetal heart. 


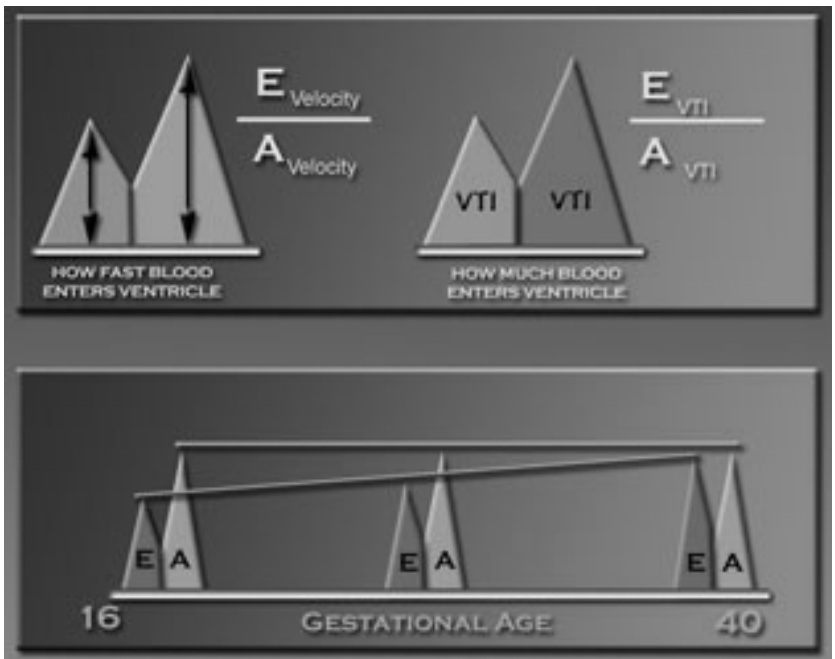

Fig. 3. This illustrates changes in the $\mathrm{E}$ and A waves as a function of the age of the fetus. As the fetus ages, the $\mathrm{E}$ wave form increases in height, representing an increase in speed as blood enters the ventricular chambers during the early filling phase of diastole. However, the A wave form does not increase in speed as the fetus ages. This suggests that the speed of blood resulting from atrial contraction remains unchanged, irrespective of the age of the fetus.

\subsection{E/A ratio}

This is a measurement of the compliance or stiffness of the ventricles as blood enters the chamber during diastole. In certain fetal conditions the measurement of this ratio may be altered.

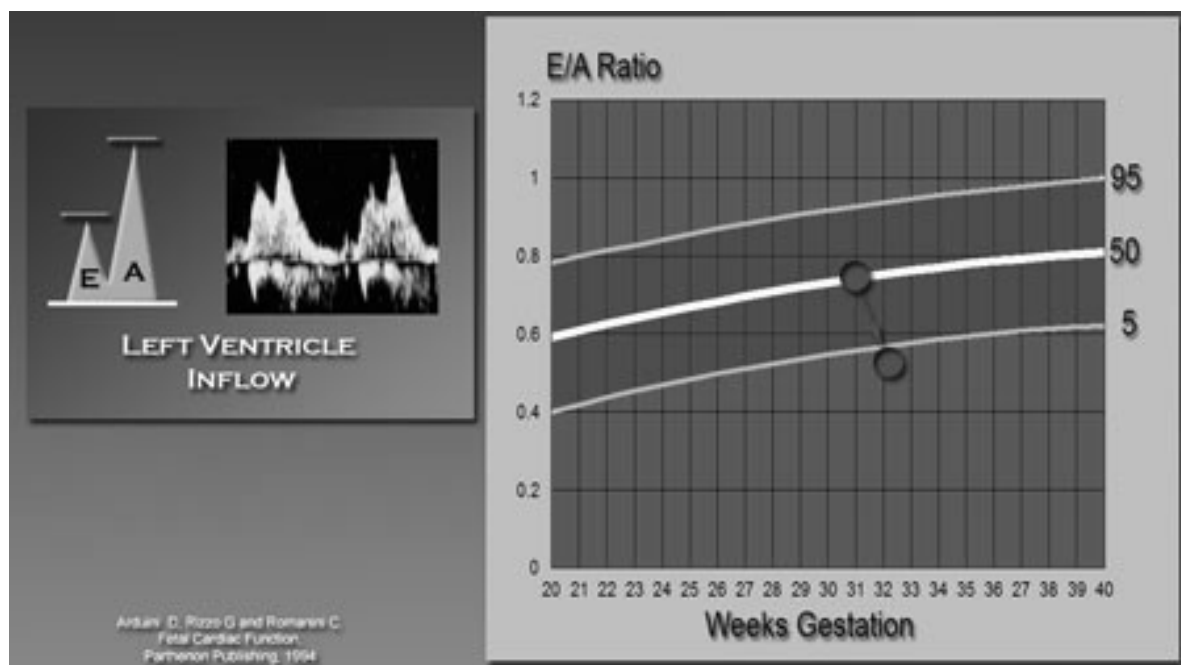

Fig. 4. 


\subsection{Peak velocity}

This measures the speed at which blood is ejected from the ventricles. When the heart is not functioning properly, then the peak velocity may decrease.

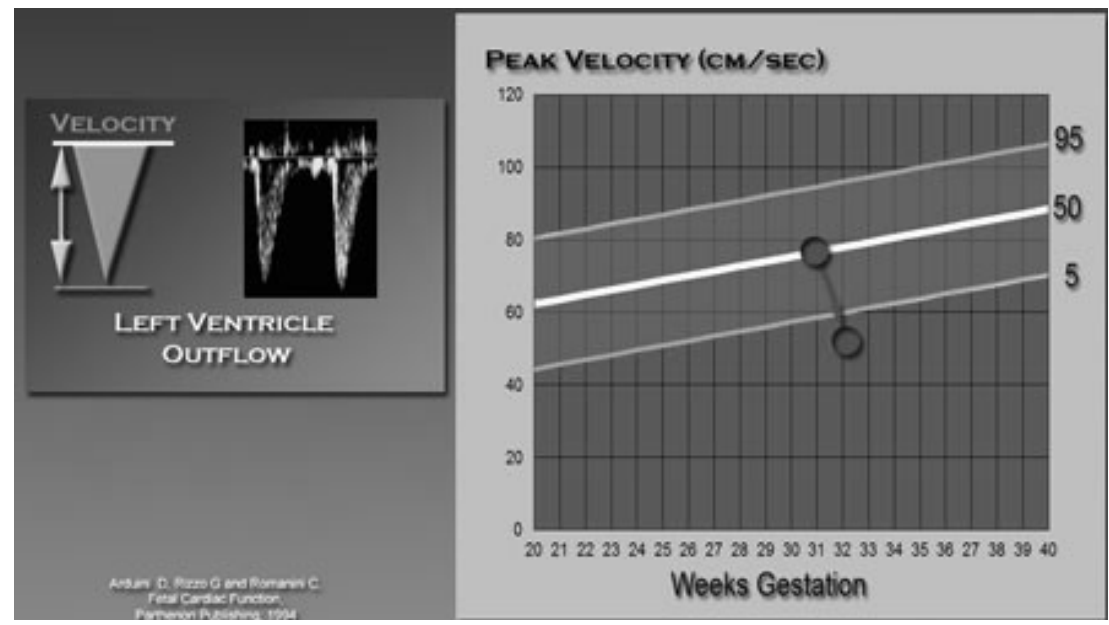

Fig. 5. This illustrates the normal range for the peak velocity of the aorta. If this decreases, this suggests cardiac dysfunction.

\subsection{Time-to-peak velocity}

This is a measure of how much resistance there is to blood as it is being pumped out of the ventricle. If the value increases, this means there is less resistance than normal. If it decreases, this means that there is more resistance to blood flow. This is often observed in fetuses with abnormal growth in which the fetus is smaller than normal.

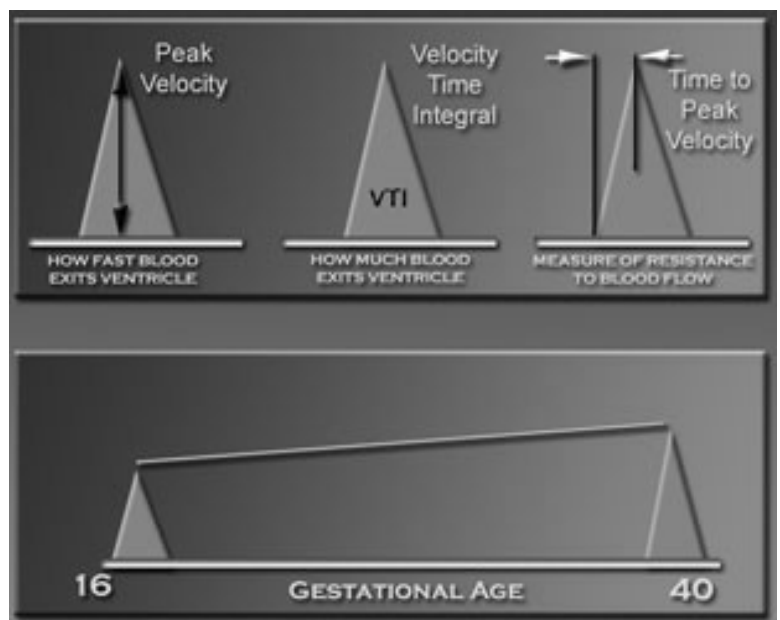

Fig. 6. 


\subsection{Pulsed doppler ultrasound examination of the heart}

Pulsed Doppler ultrasound consists of displaying the blood flow patterns in a waveform. The pulsed Doppler enables the physician to record different flow patterns during the cardiac cycle from specific parts of the heart. From these waveforms measurements can be made to assist the physician in the interpretation of blood flow into and out of the heart.

\subsubsection{Pulsed doppler relate to the electrocardiogram}

The electrocardiogram, also known as an EKG, is a recording of the electrical activity of the heart during the cardiac cycle. To understand the pulsed Doppler waveform recorded from the heart researchers have compared it to the EKG.

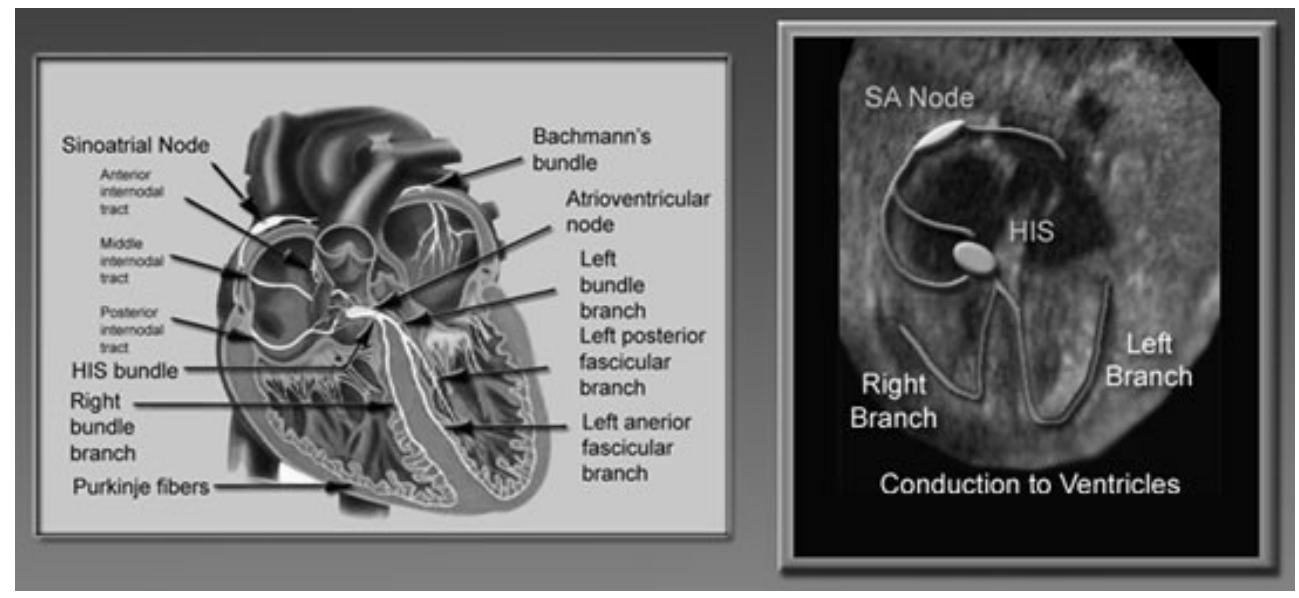

Fig. 7. This illustrates the electrical conduction of the heart.

The electrical signal originates in the SA Node located near the right atrium. It is first sent the atrial walls, resulting in contraction of the atrial chambers. The signal then is transmitted to the AV Node (green) to the ventricles. When this occurs the ventricles contract.

\subsubsection{Doppler waveforms different when recorded from the right and left sides of the heart}

Yes, the waveforms are different. For example, when the pulsed Doppler is recorded from the left ventricle the diastolic and systolic waveforms can be recorded at the same time. The reason for this is because the mitral and aortic valves are next to each other. However, these valves are not close together for the right ventricle and the waveforms must be recorded separately from different locations within the heart.

This compares the pulsed Doppler waveforms recorded from within the left and right ventricles (inflow) and the pulmonary and aortic outflow tracts (outflow). The waveforms from the inflow tracts are different because the left ventricle displays two waveforms. This is because the mitral and aortic valves are adjacent to each other, resulting in both waveforms being recorded simultaneously. 
However, the aortic waveform within the left ventricle represents the flow exiting the left ventricle before it exits through the aortic valve.

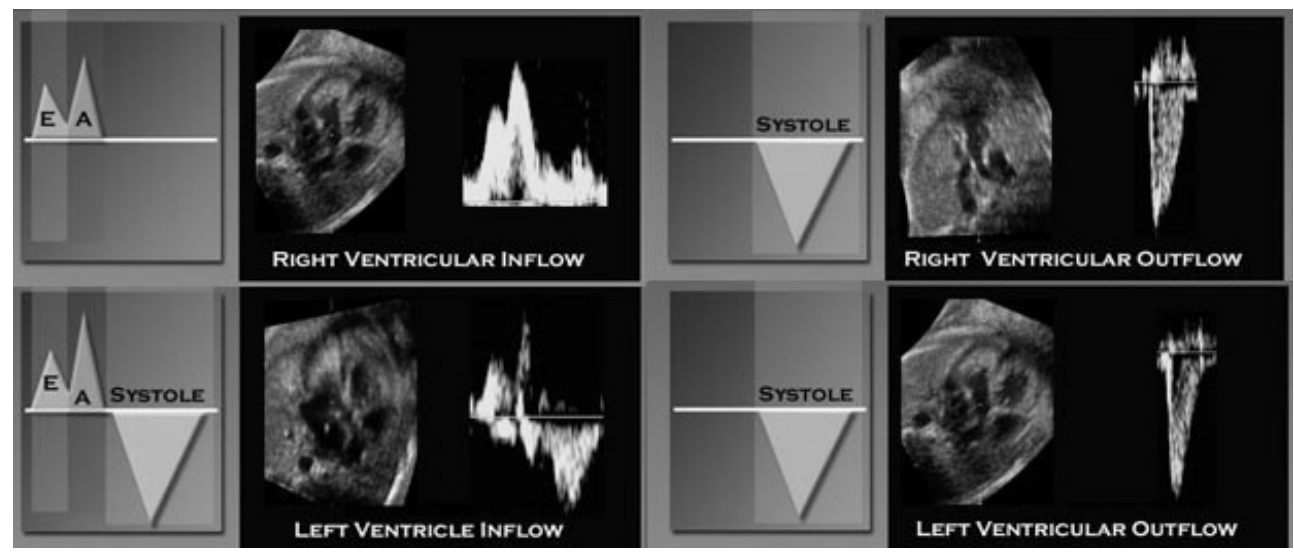

Fig. 8 .

\subsection{Equipment}

Ultrasound systems used for fetal echocardiography should have capabilities for performing 2-dimensional,M-mode, and Doppler imaging.The requirements of fetal echocardiography are more stringent than for an infant or child with congenital or acquired heart disease .This is due to the increased demands for both spatial and temporal resolution.Anatomic surveys require axial resolution of $1 \mathrm{~mm}$ or less and thiss is particularly important given the small size of critical fetal cardiac structures.Frames rates of 80 to $100 \mathrm{~Hz}$ are frequentlyneeded to view important events occuring at heart rates in excess of 140 beats per minute.TO meet these requirements,imaging systems need to be optimally configured.In general,system settings are adjusted to minimize persistence and spatial averaging and to increase frame rate.All modalites of Doppler including color, pulse, high pulse repetition frequency, and continuous wave should be available.Tissue Doppler imaging has been recently applied in the assessment of fetal arrhythmania.Harmonic imaging is useful when acoustic penetration is diffucult such as in the presence of maternel obesty.Phased array transducers with fundamental frequencies between 4 and $12 \mathrm{MHz}$ are geberally used.Curvilinear ear probes may be helpful given the wider near-field of wiev.High frequency transducers with a narrower footprint commonly used in echocardiography of infants may also be helpful.

\subsection{Examination technique}

Although the goal is to achieve visualization of each of the essential components,not all will be visualized in every fetus at every examination.Fetal position in the uterus or increased activity may limit the ability to ontain visualization of each of the components.The number of vessels in the umblical cord is counted and Doppler sampling of the umblical artery and umblical vein is performed.After establishing the position of the fetus and the right/left and anterior/posterior orientation, and initial survey of the fetus is used to estimate the gestational age and to establish abdominal situs and cardiac position. The presence or 
absence of fluid in the pericardial,pleural, or peritoneal space should be noted.The position of the inferior vena cava and descending aorta at the level of of the diaphragm are established.Multiple scanning positions and sweeps are necessary to adequately image the fetal heart.Suggested views are described below with a brief explanation of how to achieve the view an the structures generally well seen.Reference sources are available, which illustrate these views in detail.The authors recognize that based on operator style, alternative or additional sweeps and views may be utilized to image the various structures of the fetal heart and still accomplish a comprehensive fetal echocardiogram.

\subsection{Essential components of the fetal echocardiogram}

\subsubsection{Feature essential component}

- $\quad$ Anatomic overview Fetal number and position in the uterus

- Establish stomach position and abdominal situs

- Establish cardiac position

- Biometric examination Cardiothoracic ratio

- Biparietal diameter

- Femur length

- Cardiac imaging views/sweeps Four-chamber view

- Four-chamber view angled towards great arteries ("Five-chamber" view)

- Long-axis view (left ventricular outflow)

- Long-axis view (right ventricular outflow)

- Short-axis sweep (cephalad angling includes "3 vessel" view

- Caval long-axis view

- Ductal arch view

- Aortic arch view

- Doppler examination Inferior and superior vena cava

- Pulmonary veins

- Hepatic veins

- Ductus venosus

- Foramen ovale

- Atrioventricular valves

- Semilunar valves

- Ductus arteriosus

- Transverse aortic arch

- Umbilical artery

- Umbilical vein

- Measurement data Atrioventricular valve diameter

- Semilunar valve diameter

- Main pulmonary artery

- Ascending aorta

- Branch pulmonary arteries

- Transverse aortic arch

- Ventricular length

- Ventricular short-axis dimensions

- Examination of rhythm and rate M-mode of atrial and ventricular wall motion

- Dopplerexamination of atrial and ventricular flow patterns 
Structures viewed in the 4- and 5- chamber view

- Atrial and ventricular size

- Atrial and ventricular septae

- Atrioventricular size and function

- Coronary sinus

- Ventricular function in long axis

- Semilunar valve function (may not, however, be optimal to differentiate aorta from main pulmonary artery)

- Pulmonary veins

Structures viewed in the cardiac short-axis sweep

- Pulmonary venous return

- Inferior vena cava and hepatic veins

- Ventricular short-axis dimensions

- Ventricular-arterial relationship

- Right ventricular outflow tract

- Branch pulmonary arteries and origin

- Caval connections

- Innominate vein

- Ductus arteriosus

- Determination of arch sidedness and branching

Structures viewed in the cardiac long-axis sweep

- Superior and inferior vena cava

- Left ventricular outflow tract

- Ascending aorta

- Great vessel connection and size

- Ductus arteriosus and proximal ductal arch

Structures viewed in the caval long-axis view

- Superior vena cava

- Inferior vena cava and eustachian valve

- Patent foramen ovale

- $\quad$ Right pulmonary artery

Structures viewed in the ductal and aortic arch views

- Main pulmonary artery

- Branch pulmonary arteries

- Patent ductus arteriosus and direction of flow

- Aortic arch dimension (ascending, transverse, isthmus, and descending)

- Direction of flow in the aortic arch

Journal of the American Society of Echocardiography

808 Pediatric Council of the American Society of Echocardiography July 2004 


\section{Coarctation of aorta}

The narrowed segment called coarctation can occur anywhere in the aorta, but is most likely to happen in the segment just after the aortic arch. This narrowing restricts the amount of oxygen-rich (red) blood that can travel to the lower part of the body. Varying degrees of narrowing can occur.

The more severe the narrowing, the more symptomatic a child will be, and the earlier the problem will be noticed. In some cases, coarctation is noted in infancy. In others, however, it may not be noted until school-age or adolescence. Seventy-five percent of children with coarctation of the aorta also have a bicuspid aortic valve - a valve that has two leaflets instead of the usual three. Coarctation of the aorta occurs in about 8 percent to 11 percent of all children with congenital heart disease. Boys have the defect twice as often as girls do.
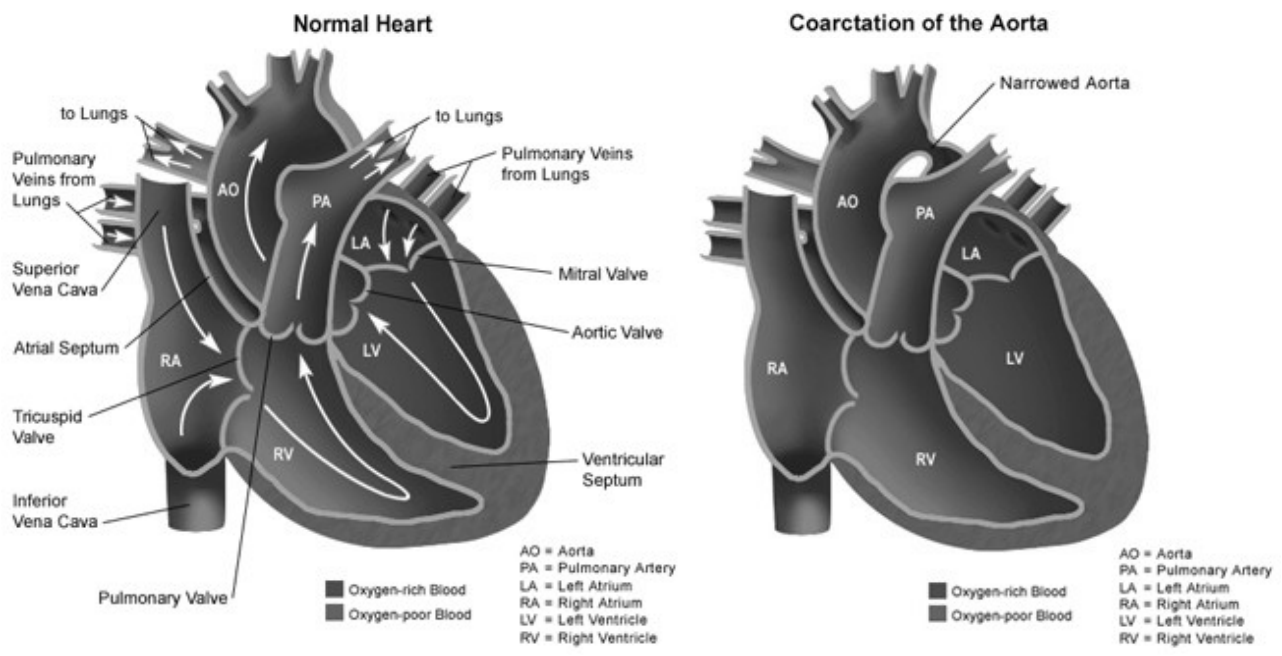

Fig. 9.

\section{Hypoplastic left heart syndrome}

Hypoplastic left heart syndrome (HLHS) is a combination of several abnormalities of the heart and great blood vessels. It is a congenital (present at birth) syndrome, meaning that the heart defects occur due to abnormal underdevelopment of sections of the fetal heart during the first 8 weeks of pregnancy. In the normal heart, oxygen-poor (blue) blood returns to the right atrium from the body, travels to the right ventricle, then is pumped through the pulmonary artery into the lungs where it receives oxygen. Oxygen-rich (red) blood returns to the left atrium from the lungs, passes into the left ventricle, and then is pumped out to the body through the aorta.

\section{Transposition of the great arteries}

In transposition of the great arteries, the aorta is connected to the right ventricle, and the pulmonary artery is connected to the left ventricle - the exact opposite of a normal heart's 
anatomy. Oxygen-poor (blue) blood returns to the right atrium from the body, passes through the right atrium and ventricle, then goes into the misconnected aorta back to the body. Oxygen-rich (red) blood returns to the left atrium from the lungs, passes through the left atrium and ventricle, then goes into the pulmonary artery and back to the lungs. Two separate circuits are formed - one that circulates oxygen-poor (blue) blood from the body back to the body, and another that recirculates oxygen-rich (red) blood from the lungs back to the lungs.
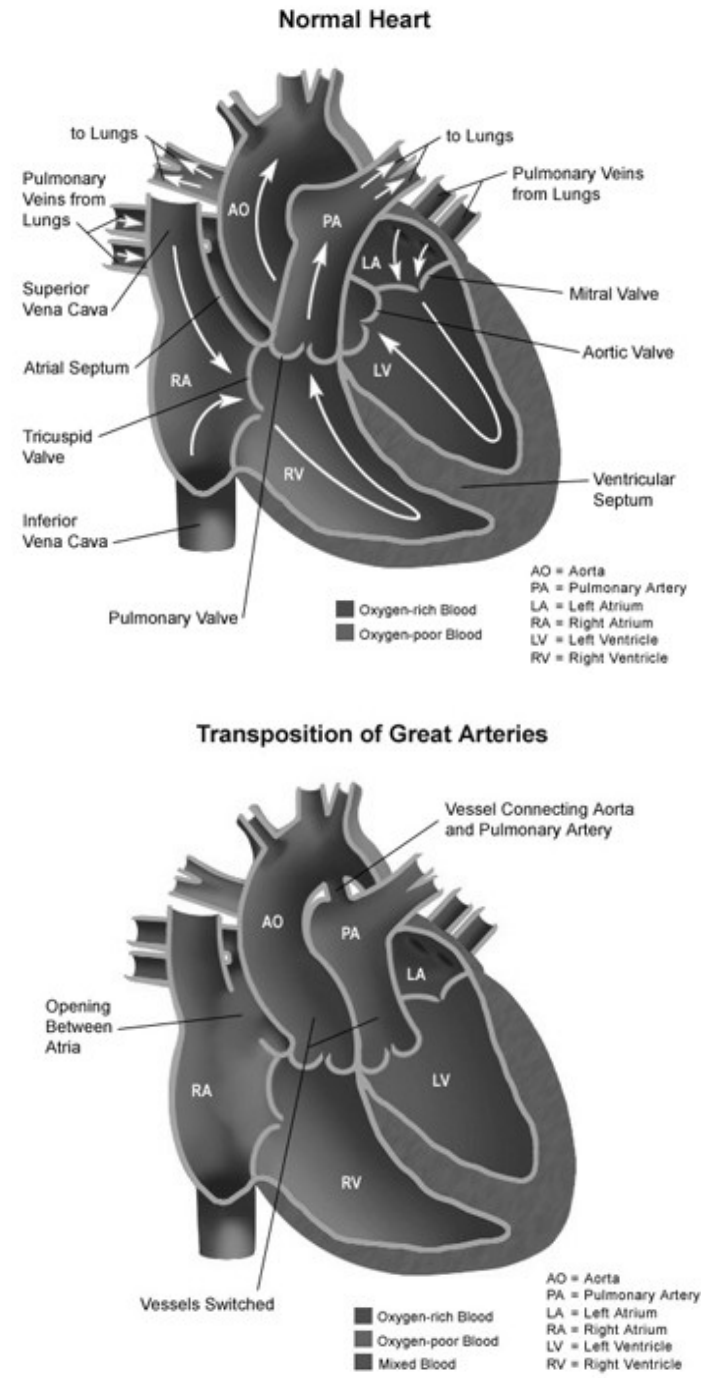

Fig. 10. 


\section{Pulmonary stenosis and atresia}

Pulmonary stenosis and pulmonary atresia with intact ventriculer septum represent $9 \%$ and about $\% 2$ off all cardiac anomalies,respectively. The most common form of pulmonary stenosis is the valvar type,due to the fusion of the pulmonary leaflets.Hemodynamics are altered proportionally to the degree of the stenosis.The work of the right ventricle is increased,as well as the pressure,leading to hypertrophy of the ventriculer walls.

Pulmonary atresia with intact ventriculer septum in infants is usually associated with a hypoplastic righy ventricle.Prenatal diagnosis of pulmonary atresia with intact ventriculer septum relies on the demonstration off a small pulmonary artery with an atreticpulmonary valve.

\section{Ebstein's anomaly}

The color Doppler defines the underlying pathology by demonstrating abnormal blood flow back into the right atrium from the right ventricle. The abnormal flow originates from a displaced tricuspid valve which is located lower in the ventricle than it should be. This is called Ebstein's malformation often seen in women who take anti-depressants such as Lithium.

\section{Aortic stenosis}

In general, the narrowing is found at the level of the aortic valve and a simple stenosis is rarely detected in the four-chamber view. However, a critical aortic stenosis is associated with a dilated and hypokinetic left ventricle with an echogenic endocardium, as a sign of endocardial fibroelastosis. Simple aortic stenosis can be detected only by using color Doppler. Antegrade turbulent flow (aliasing) is a characteristic finding in the five-chamber view. Pulsed Doppler analysis shows high velocities (more than $2 \mathrm{~m} / \mathrm{s}$ ) and a characteristic aliasing pattern. Continuous wave Doppler is therefore necessary to confirm the diagnosis. In critical aortic stenosis, there is antegrade turbulent flow across the aortic valve, but peak systolic velocities can vary from more than $2 \mathrm{~m} / \mathrm{s}$ to values within the normal range, as an expression of left ventricular dysfunction. Due to the high pressure in the left ventricle, both a mitral regurgitation and a left to- right shunt at the level of the foramen ovale are found. In severe left ventricular dysfunction, a retrograde flow is seen within the aortic arch.

\section{Hypoplastic right ventricle}

In this condition, the aortic valve is generally atretic or severely stenotic and the left ventricle diminutive and non-contractile. The mitral valve is either atretic or stenotic. Color Doppler demonstrates reduced or absent diastolic filling of the left ventricle. In the four-chamber view, there is unilateral perfusion of the right ventricle. Often, there is mild tricuspid regurgitation. Careful examination of the intra-atrial communication shows an abnormal left-to-right shunt. In hypoplastic left heart syndrome, there is retrograde perfusion of the neck vessels and coronary arteries which can also be used for the differential diagnosis. Using color Doppler, it is then possible to confirm the diagnosis by demonstrating, in the three-vessel view, the retrograde perfusion in the hypoplastic aortic arch. 
The color Doppler defines the underlying pathology by demonstrating the flow patterns within the heart.This is the labeled image of the pathology demonstrating several features. When the heart fills with blood (diastole) blood is observed filling only the left ventricle. When the heart begins to contract (systole) blood is observed going across the ventricular septal defect to fill the smaller right ventricle.

The arrows illustrate the ventricular septal defect (VSD). RA=right atrium, LA=left atrium, $R V=$ right ventricle, $L V=$ left ventricle.

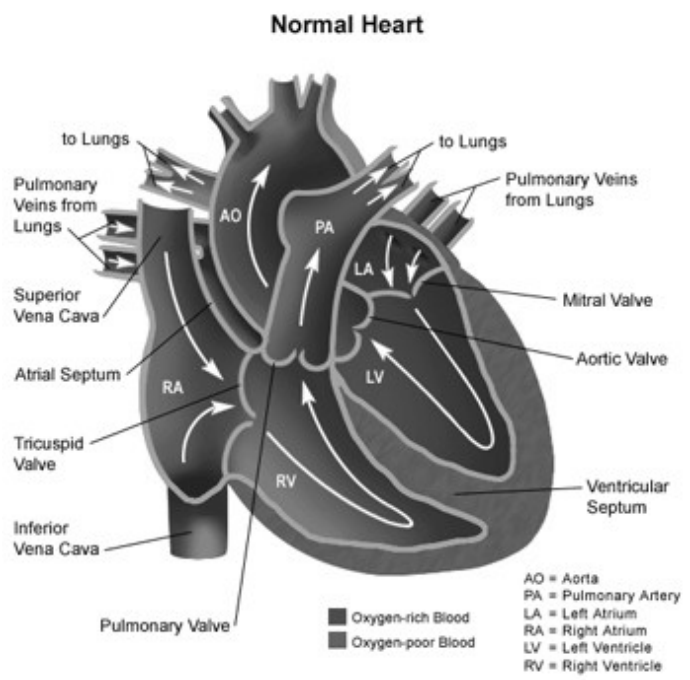

Hypoplastic Left Heart Syndrome

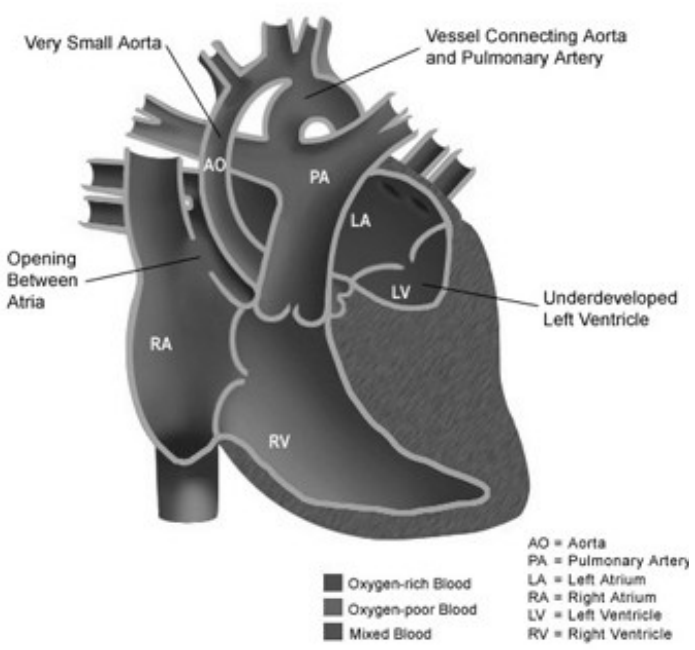

Fig. 11. 


\section{Tricuspid regurgitation}

This image illustrates the four-chamber view using 2D ultrasound on the left and color Doppler on the right. Tricuspid regurgitation cannot be demonstrated using 2D ultrasound. This finding is important because tricuspid regurgitation is associated with an increased risk for Down syndrome when it is observed during the first or second trimeters of pregnancy.

$\mathrm{RA}=$ right atrium, $\mathrm{LA}=$ left atrium, $\mathrm{RV}=$ right ventricle, $\mathrm{LV}=$ left ventricle.

The right atrium is enlarged with what appears to be an abnormal triccolor Doppler on the right. Tricuspid regurgitation cannot be demonstrated using $2 \mathrm{D}$ ultrasound. This finding is important because tricuspid regurgitation is associated with an increased risk for Down syndrome when it is observed during the first or second trimeters of pregnancy.

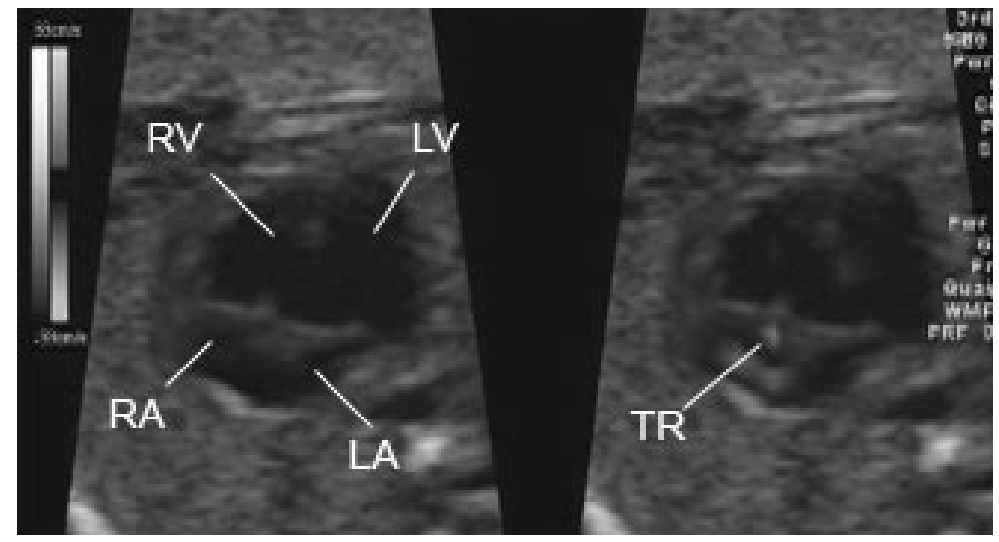

Fig. 12. RA=right atrium, $L A=l e f t$ atrium, $R V=$ right ventricle, $L V=l e f t$ ventricle.

\section{Ventricular septal defect}

The defect can be either situated in the inlet, in the muscular part or, most commonly, in the perimembranous part of the ventricular septum. The defect can be suspected by twodimensional ultrasound examination if it is larger than $3 \mathrm{~mm}$. Color Doppler can help to identify small muscular septal defects. Although right and left ventricular pressures are quite equal prenatally, a bidirectional shunt across the defect is present. The best approach to examine a septal defect with color Doppler is the perpendicular insonation of the interventricular septum. In cases of an obstruction of an outflow tract, there is an unidirectional shunt to the contralateral side; in a ventricular septal defect with aortic stenosis, there is a left-to-right shunt. 
This is the labeled image of the pathology demonstrating the shunting ventricular septal defect (VSD) easily identified with color Doppler ultrasound RA=right atrium, LA=left atrium, $R V=$ right ventricle, $L V=l$ eft ventricle.

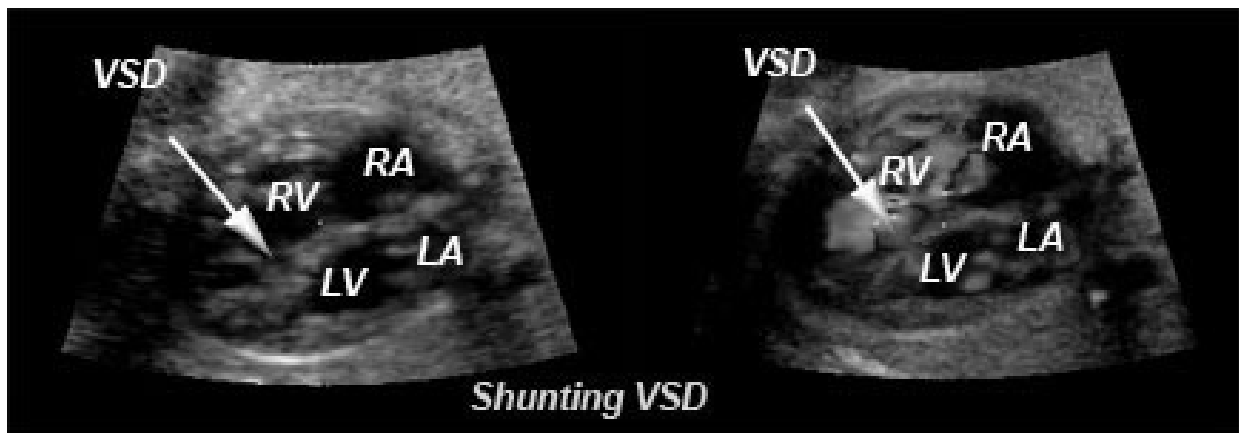

Fig. 13.

\section{Other cardiac anomalies and arrhythmias}

- Atrioventricular septal defects are a more relevant entity mostly because of the very frequent association with other anomalies such as trisomy 21;diagnosis of this defect is simpler although false-negatives may occur.

- Tricuspid dysplasia and Ebstein's malformation of the tricuspid valva may be complicated by severe tricuspid insufficiency, cardiomegaly,and hydrops;such combination is most frequently lethal,with very few infants surviving.

- Irreguler paterns of fetal heart rhythms are frequent.short periods of tachycardia,braycardia, and ectopic beats as well are very commonly seen,and in the vast majority of cases have no clinical significanca.A sustained bradycardia of less than $100 \mathrm{bpm}$, a sustained tachycardia of more than $200 \mathrm{bpm}$ and irregular beats occuring more than 1in 10 should be considered obnormal and require further investigation. The techniques of choice for the diagnosisof fetal dysrhythmias are M-mode and/or spectral Doppler ultrasound.

- $\quad$ premature atrial or ventriculer beats are by far the most frequentfetal arrhythmias. They are benign , are not associated with an increased risk of cardiac malformations, and tend to disapper throughout gestation.Serial monitoring has been recommended because, thet sometimes can evolve toward fetal tachycardia.

- fetal tachycardias are potentially serious dysrhythmias that may cause fetal hydrops and perinatal death.

- congenital heart block may accur either as a consequence of a cardiac malformation or because of transplacental passage of maternal autoimmune antibodies. 


\section{Summary}

The fetal echocardiogram is a unique ultrasound examination, which differs from the antenatal obstetrical ultrasound and from conventional echocardiogram in the infant,child,or adult.A unique ,high level set of skills and knowledge is required in order to perform this test.Diagnosis of cardiac defect is posibble ;however, a spesific examination is required (fetal echocardiogram)and this usually performed in pregnancies with an increased risk.The sensivity is in range of $80 \%$..Most of the severe cardiac anomalies can be recognized by at least mid-gestation. While performing a standard sonogram from midgestation on,it is recommended to obtain a four-chamber view of the heart ; the sensitivity of this approach varies in different studies,but the general consensus is that is an acceptable approach.

\section{References}

Abramowicz JS, Kossoff G, Marsal K, Ter Haar G. Literature review by the ISUOG bioefects and safety committee. Ultrasound Obstet Gynecol 2002;19:318-9.

Allan L, Hornberger L, Sharland G, editors. Textbook of fetal cardiology. London: Greenwich Medical Media; 2000.

Berning RA, Silverman NH, Villegas M, Sahn DJ, Martin GR, Rice MJ. Reversed shunting across the ductus arteriosus or atrial septum in utero heralds severe congenital heart disease. J Am Coll Cardiol 1996;27:481-6.

Buskens E, Grobbee DE, Frohn-Mulder IME, Stewart PA, Juttmann RE, Wladimiroff JW, et al. Efficacy of routine fetal ultrasound screening for congenital heart disease in normal pregnancy. Circulation 1996;94:67-72.

Carvalho JS, Mavrides E, Shinebourne EA, Campbell S, Thilaganathan B. Improving the effectiveness of routine prenatal screening for major congenital heart defects. Heart 2002;88:387-91.

Deane C, Lees C. Doppler obstetric ultrasound: a graphical display of temporal changes in safety indices. Ultrasound Obstet Gynecol 2000;15:418-23.

Fouron JC, Zarelli M, Drblik SP, Lessard M. Normal flow velocity profile of the fetal aortic isthmus through normal gestation. Am J Cardiol 1994;74:483-6.

Ghi T, Huggon IC, Zosmer N, Nicolaides KH. Incidence of major structural cardiac defects associated with increased nuchal translucency but normal karyotype. Ultrasound Obstet Gynecol 2001;18:610-4.

Glickstein JS, Buyon J, Friedman D. Pulsed Doppler echocardiographic assessment of the fetal PR interval. Am J Cardiol 2000;86:236-9.

Hansen M, Kurinczuk JJ, Bower C, Webb S. The risk of major birth defects after intracytoplasmic sperm injection and in vitro fertilization. $N$ Engl J Med 2002;346:725-30.

International Society of Ultrasound in Obstetrics and Gynecology (ISUOG). Safety statement, 2000. Ultrasound Obstet Gynecol 2000;16:594-6.

Journal of the American Society of Echocardiography Volume 17 Number 7 Pediatric Council of the American Society of Echocardiography. 
Kleinman C, Donnerstein R, Jaffe C, DeVore G, Weinstein EM, Lynch DC, et al. Fetal echocardiography. A tool for evaluation of in utero cardiac arrhythmias and monitoring of in utero therapy. Am J Cardiol 1983;51:237-43.

Kurjak A. Are color and pulsed Doppler sonography safe in early pregnancy? J Perinat Med 1999;27:423-30.

Miller MW, Brayman AA, Abramowicz JA. Obstetric ultrasonography: a biophysical consideration of patient safety-the "rules" have changed. Am J Obstet Gynecol 1998;179:241-54. 1. Hoffman JI, Kaplan S. The incidence of congenital heart disease. J Am Coll Cardiol 2002;39:1890-900.

Nelson NL, Filly RA, Goldstein RB, Callen PW. The AIUM/ ACR antepartum obstetrical sonographic guidelines: expecta- Journal of the American Society of Echocardiography Volume 17 Number 7 Pediatric Council of the American Society of Echocardiography indications for detection of anomalies. J Ultrasound Med 1993;4:186-96.

Phillipos EZ, Robertson MA, Still KD. The echocardiographic assessment of the human foramen ovale. J Am Soc Echocardiogr 1994;7:257-63.

Quinones MA, Douglas PS, Foster E, Gorcsan J, Lewos JF, Pearlman AS, et al. ACC/AHA clinical competence statement on echocardiography: a report of the American College of Cardiology/American Heart Association/American College of Physicians-American Society of Internal Medicine task force on clinical competence (committee on echocardiography). J Am Coll Cardiol 2003;41:687-708.

Rein AJ, O'Donnell C, Geva T, Nir A, Perles Z, Hashimoto I, et al. Use of tissue velocity imaging in the diagnosis of fetal cardiac arrhythmias. Circulation 2002;106:182733.

Schmidt KG, Silverman NH, Van Hare GF, Hawkins JA, Cloez JL, Rudolph AM. Twodimensional echocardiographic determination of ventricular volumes in the fetal heart. Circulation 1990;81:325-33.

Sharland GK, Allan LD. Normal fetal cardiac measurements derived by cross-sectional echocardiography. Ultrasound Obstet Gynecol 1992;2:175-81.

Sklansky M, Tang A, Levy D, Grossfeld P, Kashani I, Shaughnessy R, et al. Maternal psychological impact of fetal echocardiography. J Am Soc Echocardiogr 2002;15:159-66. American College of Radiology Standard for the Performance of Antepartum Obstetrical Ultrasound.

Standards for the Performance of the Antepartum Obstetrical Ultrasound Examination. Copyright 1994, by the American Institute of Ultrasound in Medicine.

Stumpflen I, Stumpflen A, Wimmer M, Bernaschek G. Effect of detailed fetal echocardiography as part of routine prenatal ultrasonographic screening on detection of congenital heart disease. Lancet 1996;348:854-7.

Tan J, Silverman NH, Hoffman JIE, Villegas M, Schmidt KG. Cardiac dimensions determined by cross-sectional echocardiography in the normal human fetus from 18 weeks to term. Am J Cardiol 1992;70:1459-67.

Tworetzky W, McElhinney DB, Reddy VM, Brook MM, Hanley FL, Silverman NH. Improved surgical outcome after fetal diagnosis of hypoplastic left heart syndrome. Circulation 2001;103:1269-73. 
Verheijen PM, Lisowski LA, Stoutenbeek P, Hitchcock JF, Brenner JI, Cope JA, et al. Prenatal diagnosis of congenital heart disease affects preoperative acidosis in the newborn patient. J Thorac Cardiovasc Surg 2001;121:798. 


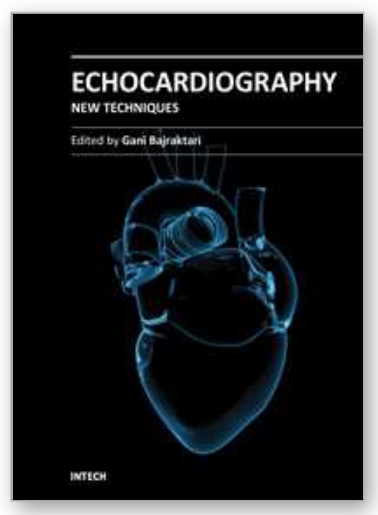

\author{
Echocardiography - New Techniques \\ Edited by Prof. Gani Bajraktari
}

ISBN 978-953-307-762-8

Hard cover, 218 pages

Publisher InTech

Published online 18, January, 2012

Published in print edition January, 2012

The book "Echocardiography - New Techniques" brings worldwide contributions from highly acclaimed clinical and imaging science investigators, and representatives from academic medical centers. Each chapter is designed and written to be accessible to those with a basic knowledge of echocardiography. Additionally, the chapters are meant to be stimulating and educational to the experts and investigators in the field of echocardiography. This book is aimed primarily at cardiology fellows on their basic echocardiography rotation, fellows in general internal medicine, radiology and emergency medicine, and experts in the arena of echocardiography. Over the last few decades, the rate of technological advancements has developed dramatically, resulting in new techniques and improved echocardiographic imaging. The authors of this book focused on presenting the most advanced techniques useful in today's research and in daily clinical practice. These advanced techniques are utilized in the detection of different cardiac pathologies in patients, in contributing to their clinical decision, as well as follow-up and outcome predictions. In addition to the advanced techniques covered, this book expounds upon several special pathologies with respect to the functions of echocardiography.

\title{
How to reference
}

In order to correctly reference this scholarly work, feel free to copy and paste the following:

Ahmet Cantug Caliskan (2012). Fetal Echocardiography, Echocardiography - New Techniques, Prof. Gani Bajraktari (Ed.), ISBN: 978-953-307-762-8, InTech, Available from:

http://www.intechopen.com/books/echocardiography-new-techniques/fetal-echocardiography

\section{INTECH}

open science | open minds

\section{InTech Europe}

University Campus STeP Ri

Slavka Krautzeka 83/A

51000 Rijeka, Croatia

Phone: +385 (51) 770447

Fax: +385 (51) 686166

www.intechopen.com

\section{InTech China}

Unit 405, Office Block, Hotel Equatorial Shanghai

No.65, Yan An Road (West), Shanghai, 200040, China

中国上海市延安西路65号上海国际贵都大饭店办公楼 405 单元

Phone: +86-21-62489820

Fax: +86-21-62489821 
(C) 2012 The Author(s). Licensee IntechOpen. This is an open access article distributed under the terms of the Creative Commons Attribution 3.0 License, which permits unrestricted use, distribution, and reproduction in any medium, provided the original work is properly cited. 